Augen nicht genug vom damaligen WB gewürdigte Eingabe des Majors Florian Pfaff. Dieser hatte seinen Dienst in der Bundeswehr verweigert, weil er glaubte, die Bundesrepublik würde trotz gegenteiliger Versicherungen durch bestimmte Aktionen, zum Beispiel den Schutz der US-Liegenschaften, die USA im Irak-Krieg unterstützen.

So verdienstvoll die Durchsicht der Jahresberichte seit 1990 sowie die mit den WB geführten Interviews sind, so sehr drängt sich dem Leser der Eindruck auf, dass dies mit dem Ziel geschah, angebliche Defizite zu finden, um die These von der „Betriebsblindheit“ im Amt des WB zu belegen. So ist nicht einsichtig, warum sich die WB seit den Auslandseinsätzen der Bundeswehr nicht verstärkt mit „Detailproblemen“ der Mitglieder der Streitkräfte zu beschäftigen haben, und warum durch diese Fürsorgetätigkeit den WB „die umfassende Problemsicht auf die Institution Bundeswehr verloren“" gehen sollte (S. 142). Bei einer unvoreingenommenen Durchsicht der Jahresberichte kann - wie von Rosenow unterstellt - von einer „Vernachlässigung der Kontrolle der Institution Bundeswehr gegenüber der Zivilgesellschaft“ (S. 142) nicht gesprochen werden. Folglich ist die Interpretation, die Tätigkeit der WB als „betriebsblind“ zu bezeichnen, fragwürdig. Immerhin konzediert die Autorin an einer Stelle dem ehemaligen WB Willfried Penner, dass er „darum bemüht gewesen sei, sein Amt im Interesse des Parlamentes und die Aufgabe der Kontrolle fokussierend auszuüben" (S. 97).

Insgesamt bleibt dennoch der Eindruck einer dem Amt des Wehrbeauftragten und seiner Praxis nicht gerecht werdenden Publikation.

Udo Kempf

\title{
Föderalismusreform I: Ertrag jahrzehntelanger Forschung
}

\author{
Scharpf, Fritz W.: Föderalismusreform. Kein Ausweg aus der Politikverflechtungsfalle? (Schriften \\ aus dem Max-Planck-Institut für Gesellschaftsforschung, Band 64), Campus Verlag, Frankfurt \\ am Main 2009, 174 Seiten, € 24,90.
}

Anzuzeigen ist eine Publikation, die alle aufmerksamen Beobachter des real-existierenden Föderalismus in Deutschland besonders interessieren dürfte: das neueste Buch des Föderalismusexperten Fritz Scharpf. Scharpf, emerierter Direktor des Max-Planck-Instituts für Gesellschaftsforschung, ist nicht nur ein Experte des Regierens im Mehrebenensystem, sondern gilt bekanntlich auch als Urheber der These von der Politikverflechtungsfalle. Das äußerst lesenswerte Buch handelt vornehmlich von der Föderalismusreform, erster Teil, die durch ein verfassungsänderndes Gesetz zum 1. September 2006 ins Werk gesetzt wurde.

Nach einer knappen Einleitung wird das Thema zunächst in historischer Perspektive entwickelt („Die Genealogie der Politikverflechtung“). Darin erfährt der Leser, wie sich das Verhältnis von Bund und Ländern seit 1949 entwickelte und wer für die Zunahme der Zustimmungsgesetze - und damit des Maßes an Politikverflechtung - die Hauptverantwortung trägt: die erste Große Koalition von 1966 bis 1969 und das Bundesverfassungsgericht durch eine großzügige Interpretation der alten Bedürfnisklausel des Art. 72 Abs 2 GG.

Im zweiten Kapitel („Probleme der Verflechtung“) liefert Scharpf den Ertrag seiner jahrzehntelangen Forschungen über das Regieren zwischen Bund und Ländern. Dabei lernt der 
Leser, dass die europäische Integration eine Chance der deutschen Bundesländer darstellen kann, wobei der Autor zu Recht die Bedeutung unterstreicht, die den Ländern in Europa zukäme, würden sie selbst unmittelbares Mitglied (Nordrhein-Westfalen stünde immerhin nach seiner Größe an siebter Stelle, aber auch andere Bundesländer gehörten nicht zu den kleinsten Mitgliedstaaten). Als Ausgangspunkte vor der Aufnahme der Beratungen der Föderalismusreformkommission im Jahre 2003 identifiziert Scharpf daher „drei große Themen“: den Abbau der ineffizienten Mischfinanzierung, die Beschränkung der Vetomöglichkeiten des Bundesrates und die Erweiterung der Gestaltungsspielräume der Landespolitik.

Auf dieser Basis schildert der Autor im dritten Kapitel („Föderalismusreform: Verlauf und Ergebnisse“) die Arbeit der Föderalismusreformkommission von Bund und Ländern. In einer Übersichtlichkeit, wie sie bislang in noch keinem Grundgesetzkommentar präsentiert wurde, legt er am Ende des Kapitels die konkreten Ergebnisse der Föderalismusreform dar. Der Ertrag der Reform bleibt in seinem Urteil dürftig, namentlich vor dem von ihm aufgespannten Hintergrund der Reformnotwendigkeiten. Hieraus ergibt sich das Thema des abschließenden vierten Kapitels: „Kompetenzverteilung im Mehrebenensystem“.

Hier zeigt sich die Meisterschaft des Autors, der nun die vom ihm als gegeben hingenommene Politikverflechtung ins Positive wendet und aufzeigt, wie nach seiner Auffassung das Beste aus dem Föderalismus in Deutschland gemacht werden könnte. Scharpf ist gegen eine politisch oft geforderte „klare Trennung“ der Gesetzgebungskompetenzen zwischen Bund und Ländern; vielmehr spricht er sich im Ergebnis für weitgehende Gesetzgebungsrechte des Bundes bei gleichzeitiger Einführung von Abweichungsrechten der Länder aus. Hierfür schlägt er die Einführung folgender, die seit 1994 bestehende Erforderlichkeitsklausel in Art. 72 Abs 2 GG ersetzende „Gemeinverträglichkeitsklausel“ vor: „Hat der Bund von seiner Gesetzgebungskompetenz Gebrauch gemacht, können die Länder durch Gesetz hiervon abweichende Regelungen treffen, soweit dadurch weder die Interessen anderer Länder noch die der Gesamtheit beeinträchtigt werden. Dabei sind die Vorschriften des Bundesrechts, von denen abgewichen wird, ausdrücklich zu nennen."

Der Rezensent, Geschäftsführer eines Bundesverbandes, kann die gelegentliche Erwähnung Scharpfs, wonach für die Zentralisierung nicht zuletzt auch die Verbände verantwortlich seien, nachvollziehen. In der Tat sieht er sich zum Teil in die Rolle des Föderalismusverteidigers gedrängt, wenn seine aus der unternehmerischen Praxis stammenden Mitglieder die Rechts(anwendungs)gleichheit im Bundesgebiet fordern. Er weiß also um die Sicherheit des abschließenden Urteils Scharpfs, der von einem „Föderalismus ohne Föderalisten“ ausgeht und die Ergebnisse seiner Untersuchungen deshalb in den Konjunktiv stellt. Dieser Befund muss für die nun sechzigjährige Republik kein Negativpunkt sein, wohl aber eine Staatsqualität der Länder, die sich damit einmal mehr als Fiktion und - im Ergebnis - Lebenslüge des grundgesetzlichen Gemeinwesens erweist. Fazit: Ein für alle an der Gesetzgebung in Bund und Ländern Beteiligten durchweg lesenswertes Buch. 